\title{
The Modified Cellulose Through Polyelectrolyte Membrane Techniques as an Adsorbent Candidate for removing of Dyes
}

\author{
BUDI HASTUTI ${ }^{1 *}$ and SAPTONO HADI ${ }^{2}$ \\ 'Department of Chemistry Education, Faculty of Teacher Training and Education. \\ Universitas Sebelas Maret, Indonesia. \\ 2Department of Pharmacy, Faculty of Mathematics and Natural Sciences, \\ Universitas Sebelas Maret, Indonesia. \\ ${ }^{*}$ Corresponding author E-mail: Budihastuti@ staff.uns.ac.id \\ http://dx.doi.org/10.13005/ojc/340665
}

Received: October 25, 2018; Accepted: November 21, 2018)

\begin{abstract}
Disposal of dyestuff into rivers or other water can disrupt the aquatic biota ecosystem in it. Thus the pollution of dyes in the aquatic environment needs to be overcome. One effort to reduce the dye content in water is by making adsorbent membranes based of cellulose which are biomaterials of chitosan and alginate. This aims of study was to make polyelectrolyte membranes from chitosan and alginate which will be applied as adsorbents of textile dyestuffs. The research was done by mixing chitosan gel in 2,5\% acetic acid solution with alginat gel in water for $3 \mathrm{~h}$ stirring. The solution then was printed out into a polypropylene container and dried. The formed membrane was characterized using FTIR to identify functional groups, XRD and SEM to analyze their physical characteristic. The results showed that the Chi-Alg membrane adsorbent had stability and resistance to the acidic environment. Characterization results using FTIR showed that the adsorbent has functional group of amine, carboxyl and hydrogen that identify on wave number $1597 \mathrm{~cm}^{-1}, 1635 \mathrm{~cm}^{-1}$ and $3000-3700$ $\mathrm{cm}^{-1}$ respectively. The results of XRD show that the adsorbent was semi crystalline. Furthermore, SEM data shows a solid structure of the adsorbent.
\end{abstract}

Keyword: Chitosan, Alginate, Chi-Alg, adsorbent, Dyestuff.

\section{INTRODUCTION}

Liquid waste which contains many dyes is produced by several domestic industries such as the textile industry and chemical laboratories. These textile industries produce liquid waste every day from the textile industry production process. Dyestuff waste is toxic, dangerous, stable to light, heat and oxidizing agents and difficult to degrade due to the complex structure of aromatic molecules (Kyzas et al., 2009). Environmental pollution due to waste disposal of colored substances can inhibit photosynthetic activity (Jing et al., 2013). Dyestuffs if discharged into the aquatic environment without handling beforehand can cause serious pollution to water sources which cause environmental ecology damage and can disrupt human health.

This is an Open Access article licensed under a Creative Commons license: Attribution 4.0 International (CC- BY). Published by Oriental Scientific Publishing Company @ 2018 
According to Sen and Demirer (2003) textile dyestuffs contain azo ( $\mathrm{R}-\mathrm{N}=\mathrm{N}-\mathrm{R}$ ') compounds with the same or different organic chains and benzene derivatives. Dyes themselves can cause an increase in Biological Oxygen Demand (BOD) and transmit disease through water (Gupta et al., 1988). One of the dyes that become waste in industry and chemical laboratories is methylene blue with the molecular formula $\mathrm{C}_{16} \mathrm{H}_{18} \mathrm{~N}_{3} \mathrm{SCl}$. Methylene blue is widely used in industries because methylene blue is a basic dye and has good solubility. In the coloring of the production process in the textile industry, methylene blue is bound to only about $5 \%$ while the remaining $95 \%$ is wasted as wastewater (Liu et al., 2007). According to Government Regulation No. 22 of 1990, the maximum level of methylene blue in the waters was set at $10 \mathrm{mg}$ $\mathrm{L}^{-1}$. Therefore, special handling of the methylene blue dye in the waters is needed so that its concentration in the waters can be reduced or reduced.

Today, there are many studies on wastewater treatment through the adsorption process using modified polymers in order to absorb wastewater containing heavy metals and wastewater containing harmful dyes. Compared to other methods such as filtration and sedimentation, adsorption is one method of waste treatment that does not require high costs (Gottipati et al., 2010).

One of the biomaterials that are relatively easy to obtain is chitosan. As biodegradable, inexpensive, and sufficient abundance as a biomaterial, chitosan has been used in a variety of applications, including in the medical, agricultural, manufacturing and waste treatment fields. Chitosan has been reported to function as a material capable of reducing the presence of dyes in waste. Chitosan effectively absorbs reactive and acidic dyes, especially in low pH (Tan et al., 2015). Chitosan, by its nature has a high affinity for adsorbing impurities such as heavy metals and dyes through the presence of several active groups available in this material. However, some of its properties such as only dissolving in acidic conditions, low mechanical strength, and small surface area can inhibit its adsorption ability. This makes chitosan requires modification with other materials to improve its nature (Representing et al., 2014). Modifications are needed to improve the hydrophilicity. In this study, pectin was chosen as a biomaterial to modify chitosan. Addition of other materials to chitosan was carried out to improve mechanical characteristics, swelling capacity and increase the adsorption capacity of dyestuffs (Zhang et al., 2013).

\section{METHODOLOGY}

\section{Material}

Chitosan, Alginate from Surabaya, Acetic Acid $5 \%$, Aquadest,

\section{Procedure}

\section{Preparation of adsorbent}

Synthesis of chitosan alginate to make adsorbent. Chitosan 0, $2 \mathrm{~g}$ was dispersed in $10 \mathrm{~mL}$ of acetic acid $5 \%$ and then stirring until 3 hours. Alginate $0,2 \mathrm{~g}$ was dispersed in $10 \mathrm{~mL}$ water and then stirring until 3 hours. After that, Chitosan solution was added to alginate solution and then stirring until homogeny. After all the solution is mixed, the mixture was then printed out into polypropylene container and dried in oven. After dry, the film can be peeled off from the container. The Chitosan-Alginate PEC adsorbent was ready.

Alg-Chi polyelectrolyte membrane, further washed with distilled water and dried at $60^{\circ} \mathrm{C}$, and characterized by using an infrared spectrophotometer to show functional groups. Then the membrane analyzed using X-Ray Diffraction (XRD0 to determine the stability of the membrane. And the furthermore it analyzed using Scanning Electron Microscopy (SEM) to determine the membrane morphology of the surface and cross section of the membrane.

\section{RESULT AND DISCUSSIONS}

\section{FTIR Characterization}

$-\mathrm{COOH}$ group is the dominant active group in alginate, while the dominant active group of chitosan is $-\mathrm{NH}_{2}$ group. Fourier Transform Infrared (FTIR) Spectroscopy are used to see how interaction between components and the result of synthesis Polyelectrolyte Complex Chi-Alg (PEC) Chi-Alg film. From Fig. 1, it can be seen on three spectra in the region $3000-3700 \mathrm{~cm}^{-1}$ that can be observed a broad of hydrogen-bonded $\mathrm{OH}$ groups. In this area also can be observed $\mathrm{NH}$ group stretching vibrating which overlaps with $\mathrm{OH}$ vibration for chitosan spectra. In the area of $1500-1800 \mathrm{~cm}^{-1}$ can be observed the stretching vibration of the carbonyl group on the band at $1635 \mathrm{~cm}^{-1}$ for alginate (A). While in the chitosan 
(B) spectra, in the area of $1597 \mathrm{~cm}^{-1}$ show stretching vibration $\mathrm{C}=\mathrm{O}$ for amide group. In the area around 1600$1500 \mathrm{~cm}^{-1}$ in PEC spectrum induces an amine group that interacts with alginate, that is around $1627 \mathrm{~cm}^{-1}$.

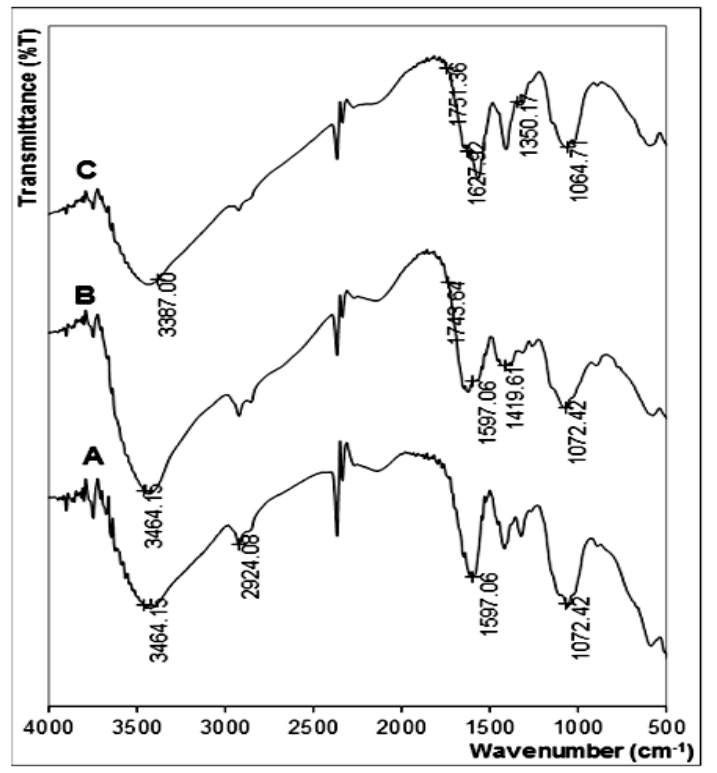

Fig. 1. FTIR spectra from film: A. Alginate; B. Chitosan; C. Alginate-Chitosan

Analysis of Chi-Pec PEC adsorbent by XRD

The phase form of the material from pure film (Alginate, Chitosan) and its modification, the membrane/film was tested using X-Ray Diffraction (XRD). XRD spectra result from alginate showed that the properties of alginate is amorphous, this was characterized by the absence of peaks which appeared anomaly, at peak $2 \theta=22^{\circ}$. The characterized the phase of chitosan from the result of XRD test is semi-crystalline and have peak at $2 \theta=22^{\circ}$ and $29^{\circ}$. In the PEC, between alginate and chitosan, the characteristics of chitosan and alginate is can be seen, it is a combination of chitosan and alginate, it causes the film to become semi-crystalline. This can be explained by the strong interaction like hydrogen bond and ionic interaction between pectin and chitosan with has destroyed the close packing of chitosan molecule for those formation of regular crystalline ${ }^{10}$. The presence of alginate in Alg-Chi PEC decreases the crystalline level of chitosan which is seen by the comparison of peak of each spectra.

\section{SEM Analysis}

Morphology of the PEC Alg-Chi adsorbent film, it can be seen using SEM test, both form the surface and cross section. From the result of SEM for surface appearance with 500X magnification both chitosan and alginate have small and homogeneous pores (Fig. 3 A and B). Fig. 4 shoaw image of Alg-Chi film from to the surface in figure $4 \mathrm{~A}$ and crossection in figure 4B. It show that PEC film give a different pattern compared to the original compounds namely alginate and chitosan. Alg-Chi PEC film more porous and high complexity. The PEC Alg-Chi adsorbent has large pores surface and more rough, thus this adsorbent has potential to be applied as a super adsorbent to bind dyes in the waters. So it implys that PEC membrane was potential used as an adsorbent candidate for dyestuffs.

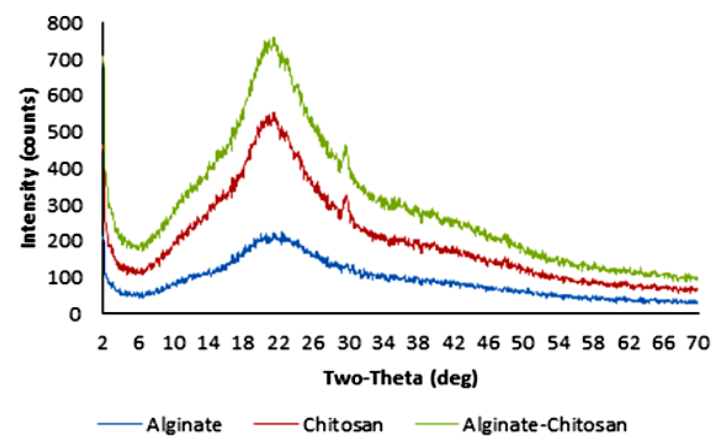

Fig. 2. XRD spectra of the film: A. Alginate; B. Chitosan; C. Alg-Chi
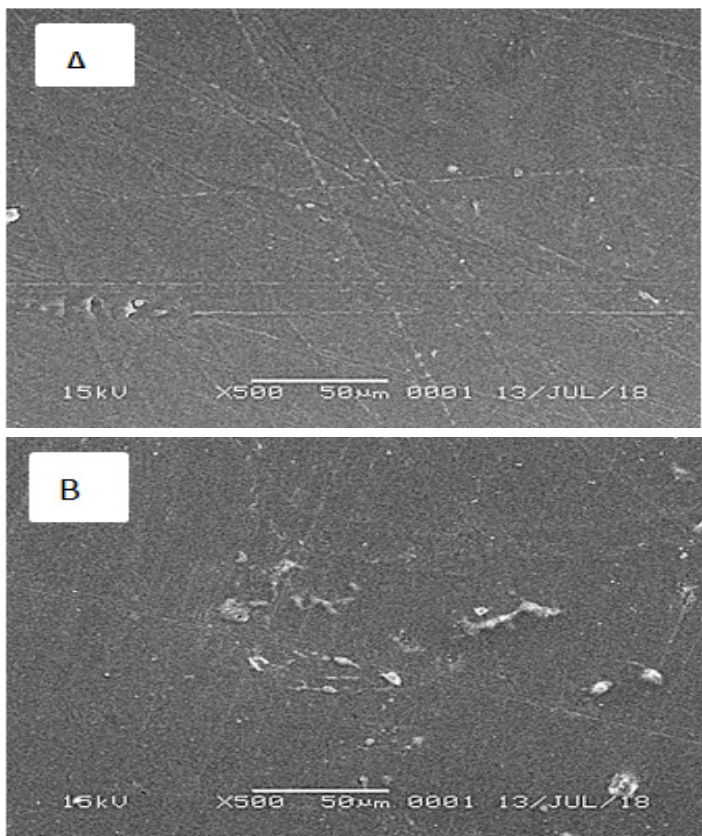

Fig. 3. Surface of the film by SEM with 500x magnification : A: Alginate, B:Chitosan 

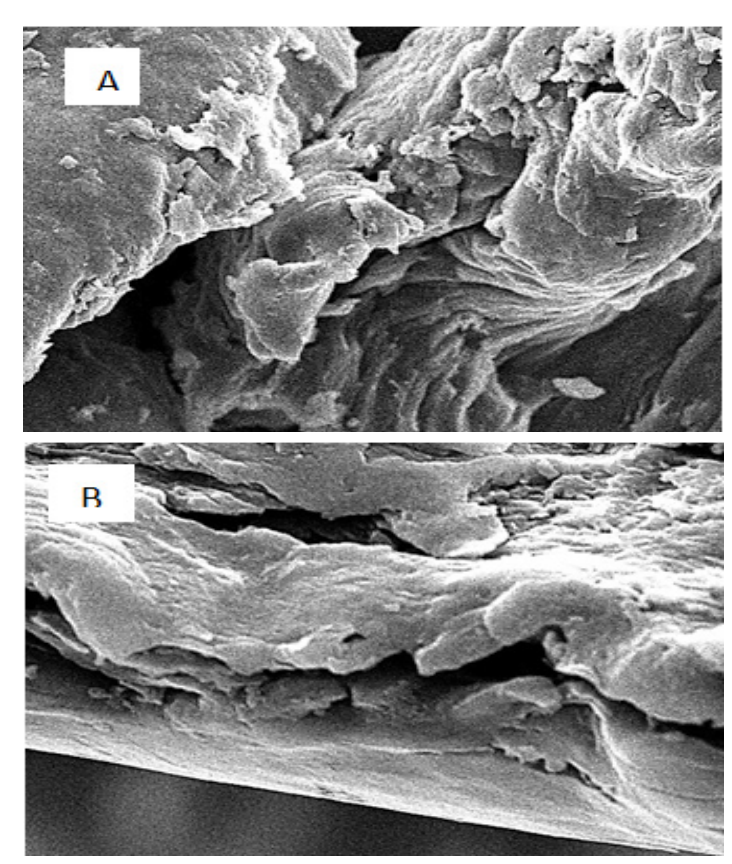

Fig. 4. The image of film by SEM with magnification 3000 x: A. Alg-Chi surface; B. Alg-Chi crossection

\section{CONCLUSION}

Alginate-Chitosan polyelectrolyte complex Alg-Chi PEC) were prepared by combine both polysaccharides Alginate and Chitosan. Based on FTIR spectroscopy, the adsorbent have active group comprise and interaction of carboxylate and amine groups. The result of characterization using XRD, show that the Alg-Chi PEC adsorbent is semi-crystalline. Based on SEM analysis, the film adsorbent has large pores with a high complexity.

\section{ACKNOWLEDGEMENT}

The authors express gratitude to the Indonesian Ministry of Research and Technology Directorate of Higher Education and Universitas Sebelas Maret for funding this research via shceme Hibah Mandatory.

\section{REFERENCES}

1. Kyzas, G.Z., Lazaridis, N.K., dan Kostoglou, M., Adsorption/desorption of A Dye by A Chitosan Derivative: Experiments and Phenomenological Modeling, Chem. Eng. J., 2014, 248, 327-336

2. Jing, Z., Dongqing, C., Guilong, Z., Chuanjie, C., Caili, Z., Guannan, Q., Kang, Z., Zhengyan, W., Adsorption of methylene blue from aqueous solution onto multiporous palygorskite modified by ion bombardment: Effect of contact time, temperature, $\mathrm{pH}$ and ionic strength, J. App. Clay Sci., 2013, 83-84, 137-143.

3. Sen, S., dan Demirer, G. N., Anerobic Treatment of Real Textile Waste Water with a Fluidzed Bed Reactor, J. Water Resour. Protec., 2003, 37, 1868-1878.

4. Gupta, G. S., Prassad, G., Panday, K. K., Singh, V. N., Removal of Chrome Dyes from Aqueous Solution by Fly Ash, J. Water Air Soil Poll., 1988, 32, 384-395.

5. Liu, L. S., Liu, C. K., Fishman, M. L., Hicks, K. B., Composite films from pectin and fish skin gelatin or soybean flour protein, J. Agr.Food.
Chem., 2007, 55(6), 2349-2355.

6. Gottipati, R. dan Mishra, S., Application of Biowaste (Waste Generated in Biodisel Plant) as an Adsorbent for the Removal of Hazardous Dye-Methylene Blue-from Aqueous Phase, Brazilian J. Chem Eng., 2010, 27(2), 357-367.

7. Tan, K.B., Vakili, M., Horri, B.A., Poh, P.E., Abdullah, A.Z., dan Salamatinia, B., Sep. Purif. Technol., 2015, 150, 229-242.

8. Vakili, M., Rafatullah, M., Salamatinia, B., Abdullah, A.Z., Ibrahim, M.H., Tan,K.B., Gholami, Z., dan Amouzgar, P., Application of Chitosan and Its Derivatives As Adsorbents for Dye Removal From Water and Wastewater: A review, Carbohyd. Polym., 2014, 113, 115130.

9. Zhang, G., Yi, L., Deng, H., dan Sun, P., Dyes Adsorption Using A SyntheticCarboxymethyl Cellulose-Acrylic Acid Adsorbnet, J. Environ. Syst., 2013, 26, 1203-1211.

10. Ghaffari A, K Navaee, M Oskoui, K BAyati, M R Tehrani. European Joutnal Pharmaceutics and Biopharmaceutics., 2007, 175-186. 